This is an Accepted Manuscript of an article published by Taylor \& Francis in

International Journal of Multilingualism on 2019, available online:

http://www.tandfonline.com/doi/full/10.1080/14790718.2018.1523173

Iturregui-Gallardo, Gonzalo. Rendering multilingualism through audio subtitles:

shaping a categorisation for aural strategies. International Journal of

Multilingualism, 2019.DOI: $\underline{10.1080 / 14790718.2018 .1523173}$

\title{
Rendering Multilingualism through Audio Subtitles: Shaping a Categorisation for Aural Strategies
}

\begin{abstract}
Multilingualism in films has increased in recent productions as a reflection of today's globalised word. Different translation transfer modes such as dubbing or subtitling are combined to maintain the film's multilingual essence when translated into other languages. Within media accessibility, audio subtitles, an aurally-rendered version of written subtitles, is used to make access possible for audiences with vision or reading difficulties.

By taking Sternberg's representation of polylingualism (1981), this article offers a categorisation of the strategies that may be used to reveal multilingualism in audiovisual content through audio subtitles similar to the way Szarkowska, Zbikowska, \& Krejtz (2013) did with subtitles for the deaf and the hard of hearing. By taking a descriptive approach, two main strategies or effects for the delivery of audio subtitles - dubbing and voice-over - are highlighted and explained. By combining these two effects with the information provided by the audio description, the levels of the categorisation are defined from more to less multilingualism-revealing: vehicular matching, selective reproduction, verbal transposition, explicit attribution and homogenising convention.
\end{abstract}

Keywords: media accessibility, audio description, audio subtitling, multilingualism, audiovisual translation

\section{Introduction}

In recent decades, society has evolved towards a more inclusive design for services and products offered to the public with a diversity of specific needs. In fact, disability or impairment are being reshaped and understood as a plain human right, thus, to be 
observed in any situation or service (Greco, 2016). In media accessibility within the field of audiovisual translation (AVT), the need for specific services to access audiovisual content has broadened to treat sensory impairments the same the same way linguistic barriers are treated (Greco, 2016, p. 24). 
Technology has undoubtedly fostered the appearance of several services that seem to follow a common trend towards the provision of on-demand variations of the same content to fulfil different specific requirements. In this light, services such as Audio Description (AD), targeted primarily - but not exclusively - at the blind and partially sighted, have slowly increased their presence in mainstream broadcast, cinema and on-line content.

Similar to the way subtitling, dubbing or voice-over create a linguistic bridge between an original language and a language known by the viewers, the $\mathrm{AD}$ is a service that allows an audience that has difficulty accessing the visuals to be able to enjoy audiovisual contents. This is achieved by providing an audio description or narration of the visual, which helps blind and partially sighted audiences to follow. In research, such accessibility services have been the subject of increasing interest in the academic field of AVT (see, for instance, the monographs by Maszerowska, Matamala, \& Orero, 2014 and Matamala \& Orero, 2016).

Sometimes in audiovisual content not only image is to be conveyed as a description for the blind and partially sighted. Text on screen, such as subtitles, needs to be adapted to enable viewers to understand and enjoy. If a blind or partially sighted user or a user with reading difficulties does not understand the original and cannot fully read the subtitles, the delivery of an aural version in the form of audio subtitles (ASTs) can help to ensure access. Although the division between dubbing and subtitling countries is far more complex (Matamala, Perego, \& Bottiroli, 2017), whereas written subtitles is a regular practice in the so-called subtitling countries, such as Sweden or the Netherlands, in other countries belonging to a stronger dubbing tradition, such as Spain or Italy, dubbing is still the usual transfer mode (Gottlieb, 2004). In the latter, subtitles are used in multilingual products where secondary languages are provided with a written 
translation in contrast to the main language(s) of the film, that is(are) dubbed, in other words, "the foreign language embedded in the "language of communication"” (Heiss, 2004, p. 214).

This article has the objective of showing the different possibilities that ASTs offer when revealing the multilingual reality of audiovisual contents. More specifically, it reproduces the categorisation created by Szarkowska et al. (2013) for the subtitles for the deaf and hard of hearing (SDH) using ASTs. First, the accessibility service of audio subtitling will be defined and its study within the field of media accessibility and AVT will be discussed. Second, multilingualism will be explored in translation studies and AVT. Sternberg's Polylingualism representation (1981) will be presented and discussed as well as its application to SDH. This will lead to the adaptation of the different categories of multilingualism-revealing strategies to audio subtitling (AST). The article ends with some concluding remarks and the presentation of possible future lines for research in multilingualism and AST.

\section{Multilingualism in AVT}

Multilingualism in films is an attempt to represent linguistic reality (De Higes-Andino, 2014). As stated by Szarkowska et al. (2013, p. 1), “directors are incorporating foreign languages into their scripts in order to add a touch of authenticity to scenes set in foreign environments, thus allowing the audience to immerse into 'the foreign"'. The treatment of multilingualism in a film has attracted the interest of scholars in AVT. It has been studied from different approaches in translation using different text typologies, such as legal or institutional texts, theatrical works or literature (see, for instance, Meylaerts, 2006). AVT research on the topic has produced a series of works which also focus on different aspects and characteristics of this type of texts. Meylaerts \& Serban (2014) point to a change in paradigm in the world of translation for audiovisual and 
stage content.

Whereas in its origins the interest within translation studies lay in the translation of a monolingual text into another text for a monolingual audience, since the 1980s and 1990s the focus has shifted to the translation and rendering of multilingual texts within broader social context (Corrius, 2008). Some studies have explored the notion of L3, the third language used in a film different from the source and the target language, in the translation process (Corrius \& Zabalbeascoa, 2011); others have compared how different transfer modes, such as subtitling and voice-over, convey multilingualism and its impact in terms of comprehension (Voellmer \& Zabalbeascoa, 2014) or how multilingualism is portrayed in a voice-over country such as Poland (Sepielak, 2016). In the case of dubbing countries, the strategies shown in multilingual films have been the object of research by Heiss (2004), who observed that multilingualism is maintained as a regular practice and when secondary languages unknown to the audience are spoken in a dubbing country such as Italy, subtitles are normally used. Other strategies include the representation of a strong accent in the dubbing of foreign languages or the technological advances found in DVDs, that allow for different services on demand according to the needs and wishes of the consumer (Heiss, 2004).

Multilingual films pose important challenges when, apart from dealing with the translation with more than one language, they have to be adapted for accessibility purposes. When secondary languages are dubbed, dialogues no longer present the problem, and only AD is needed. In content where secondary languages are subtitled, however, all the visual information has to be transferred to the aural channel. The difficulties when adapting multilingualism in films for users who cannot make use of the subtitles have been addressed by some authors (Benecke, 2012; Braun \& Orero, 2010; Harrouet, 2016; Matamala, 2014; Remael, 2012; Reviers \& Remael, 2015). It has 
been shown that, in these situations, AST is the most usual way of portraying and handling the multiplicity of languages in an audiovisual product.

\section{Audio Subtitling}

AST is an access service placed somewhere between the adaptation of standard audiovisual content for people with specific needs and the more canonical conception of text translation based on the translation proper (interlingual translation) defined by Jakobson (2000/1959) in which a message in a source language is transferred into a target language. More precisely, in the case of AST the source language (SL) is translated into a target language (TL) in the written subtitles and then delivered orally, thus, in a different channel.

ASTs or spoken subtitles (Ljunglöf, Derbring, \& Olsson, 2012; Verboom, Crombie, Dijk, \& Theunisz, 2002) are defined with the concept of "spoken or aural rendering" in the literature, examples are Nielsen \& Bothe (2008), Miesenberger, Klaus, \& Zagler (2002, p. 296), Fryer (2013, p. 194), Szarkowska \& Mączyńska (2011, p. 24), Orero (2011, p. 237), and the International Organization for Standardization \& International Electrotechnical Commission (ISO \& IEC, 2015) or the International Telecommunication Union (ITU, 2013, p. 3).

Harrouet (2016, p. 8), in a more holistic way, provides a more etymologicallydriven definition stating that the term comes from two other transfer modes in AVT: subtitling and audio description. AST, applied particularly to cinema and other fiction genres, is described as a "hybrid variant" of subtitles that transforms the dialogues of the film. The original text is "written to be spoken, then summarized and rewritten to be read as subtitles by the audience, [and has] to be read out loud again as audio subtitles" (Remael, 2014). Such hybridism places "this modality of audiovisual localisation [...] at the interface between subtitling, audio description and voice-over (Braun \& Orero, 
2010, p. 173). One of the definitions that seems to best embrace the heterogeneity of the application and form of this technique is the one provided by Reviers \& Remael (2015, p. 52):

\footnotetext{
"AST can therefore be defined as the aurally rendered and recorded version of the subtitles with a film. This spoken version of the subtitles is mixed with the original sound track. AST is usually read, sometimes acted out, by one or more voice actors. Sometimes it is produced by text-to-speech software. The subtitle text is often delivered almost literally, but it can be rewritten to varying degrees, and in addition, the recording method also varies. Usually, AST is recorded as a form of voice-over, which means that the original dialogues can be heard briefly before the translation starts. Sometimes it is recorded in a semi-dubbed form, which means that the original dialogues are substituted by a form of dubbing that is not necessarily entirely lip-sync, that is, synchronous with the lip movement of the speaker."
}

While AD, as the main access service offered for the blind and partially sighted audience, has drawn the attention in regulations and academia, references to AST are less numerous. However, AST appears in some access media regulations, for instance in countries like Sweden (Swedish Government, 2014) or Finland (Finnish Government, 2010) and has been mentioned in the ISO 20071-25 (ISO \& IEC, 2016). In academia, though, few scholars have centred their attention on this service. Some studied the application of new systems for the delivery and implementation of automatic ASTs (Mihkla et al., 2014; Nielsen \& Bothe, 2008; Thrane, 2013) and other focused on the study of AST in multilingual films adapted for blind and partially sighted audiences (Benecke, 2012; Braun \& Orero, 2010; Remael, 2012, 2014; Reviers \& Remael, 2015). Their presence in some regulations and regular broadcasting and its description and analysis in the academic field are proof of the usefulness of the service. However, less is said about the way ASTs should be implemented and the possibilities their characteristics could offer. 


\section{Research in Audio Subtitling}

Some scholars have produced works of descriptive and prescriptive nature and provide an insight into the current implementation of this service in the commercial audiovisual production of fiction. Such analyses have been carried out with both monolingual and multilingual films, audio described and audio subtitled (Braun \& Orero, 2010), or with films presenting a main language and secondary languages (Benecke, 2012; Remael, 2012); Reviers \& Remael, 2015; Matamala, 2014).

Braun \& Orero (2010) analysed the first 10 minutes of 14 audio described and audio subtitled films ${ }^{1}$ and presented the two main challenges posed by the implementation of AST: 1) that written subtitles normally condense the information and 2) that they rely on the visual input as an anchorage, which is obviously a problem for people unable to access the visuals and that subtitles omit features of spoken language that might be recovered by ASTs (pp. 175-176). From their analysis, they propose different strategies for the introduction of ASTs:

(1) Creating a change in the intonation when reading the subtitle aloud,

(2) Preceding the subtitle/caption delivery by "a subtitle/caption reads",

(3) Delivering the utterance directly in a quote within the AD content,

(4) Providing the name of the speaker in front of the corresponding subtitle, and, in a more indirect way,

(5) Including a description of the situation, such as the direction towards a character's gaze is oriented to.

Of a more descriptive approach is the work by Benecke (2012). In his article,

\footnotetext{
${ }^{1}$ Be with Me (Khoo, 2005), Borat (Charles, 2006), Brick Lane (Gavron, 2007), Bride and Prejudice (Chadha, 2004), East is East (O’Donnell, 1999), Everything is Illuminated (Schreiber, 2005), Hero (Yimou, 2004), Kung Fu Hustle (Chow, 2004), Letters from Iwo Jima (Eastwood, 2006), Munich (Spielberg, 2005), The Passion of the Christ (Gibson, 2004), The Science of Sleep (Gondry, 2006), Syriana (Gaham, 2005) and Volver (Almodóvar, 2006).
} 
different situations where ASTs are used in dubbed films are presented. In multilingual films such as The Piano (Campion, 1993), sign language is rendered in subtitles that are then voiced as ASTs. In the German polyglot Am Limit (Dunquart, 2007) the utterances by English speakers are read by the audio describer. In Inglorious Basterds (Tarantino, 2009) and Babel (González Iñárritu, 2006) different voices are used to create the ASTs of various characters speaking in a language other than the main language of the film. The AST of songs is exemplified in films such as Volver (Almodóvar, 2006), where the same female audio describer provides ASTs of the song and describes the action, which may pose some problems following the scene according to the author, or Hable con ella (Almodóvar, 2002), where a female voice provides the subtitles for the song (sung by a woman) whereas the AD is provided by a male voice.

Matamala (2014), in an article aiming to cover the potential adaptation of all types of text on-screen, also analyses the challenges that may be posed by the AD in Spanish of the text appearing on screen in Inglorious Basterds. She treats the multilingualism in the film with particular interest. In fact, English, German, French and Italian are spoken and apart from English that, as the predominant language, is dubbed, the rest of them are subtitled. She provides a comprehensive summary of the potential strategies for the delivery of ASTs. For example, she points to the possibility of not voicing the very short excerpts featuring a foreign language, which are not even subtitled for sighted audiences, when they can be considered well-known for the target audience (e.g. the French "Merci"), the action conveys the core meaning or there is a character acting as interpreter.

However, for those occasions in which subtitles are required to transfer meaning, she proposes a series of strategies such as adding the word "Subtitles" before reading them, changing the intonation, naming the character before reading the 
dialogue, or adding an audio input as earcon. Furthermore, she emphasises the following key factors to bear in mind when delivering ASTs: reading verbatim or summarising written subtitles due to time constraints, the recovery of oral markers existing in the original but deleted in the subtitles and voice's characteristics (synthetic/natural, acted/not acted and with a dubbing/voice-over effect).

Remael (2012) presents multilingualism in the Dutch/Flemish context with a project in which four films are analysed. The article, though, focuses on only two Dutch films: Oorlogswinter (Koolhoven, 2008) and Tirza (van den Berg, 2010). According to her, one of the most important problems when delivering ASTs is character recognition because, exposed to such a rich audio input (original dialogue, AST, music, sound effects), audiences may be confused. The article also draws attention to the fact that some of the Dutch actors were able to speak the foreign languages to be subtitled (for sighted audiences). This situation allowed the same actors to voice the ASTs in the film. It remains unclear whether this strategy allows for better coherence and general comprehension of the dialogues. Of great interest, however, is that these films were audio described and audio subtitled by professionals taking into account Braun \& Orero's challenges mentioned before. Remael (2012) raises four main aspects to carry out her analysis of films: the role of the AD when delivering the ASTs, the manipulation of text between written subtitle and audio subtitle, the audibility of the original lines, and the importance of intonation.

Therefore, in Oorlogswinter, the AD provides a lot of information about the position and movements of the characters and the description of facial expressions, facilitating character recognition when ASTs are heard. In this film, ASTs and written subtitles are practically identical, although some discussion about the condensed written nature of standard subtitles might arise around this point. Remael highlights the 

importance of intonation when recognising the character talking. In the film, professionals made a great effort to render the performance of the actors speaking in a foreign language into the AST.

The complexity of AST is also described in Reviers \& Remael (2015) in what they call "multimodal cohesion" and how this affects the coherence experienced by the audience. Multimodal cohesion refers to the link created between image and film dialogue based on the cohesion of references, in the sense that signs within a text cannot be duly understood without another sign. In the study of AD for blind and partially sighted audiences, such cohesion is found between dialogues and description. In this study, the multilingual film Oorlogswinter (Koolhoven, 2008), already analysed in Remael (2012), and Süskind (van den Berg, 2012) were surveyed in order to give an insight to the multimodal cohesion found in the films. The authors conclude that, after the analysis of some clips of the two films, the made-accessible film maintains its coherence thanks to the professionals creating cohesive multimodal links between the AST and the AD, thus allowing the audience to recreate the same experience in terms of narrative coherence.

In the studies on the application of AST to multilingual films, different concerns have been identified by researchers. It could be argued that one of the main concerns is comprehension by the target audience; AST should be linked to the visual clues adapted into the AD in what Reviers \& Remael (2015) call multimodal cohesion. For the correct comprehension, ASTs can be implemented following different strategies that shape them. In general, the following factors are highlighted by the authors: type of voice (male or female, synthetic or natural), whether or not subtitles have to be read aloud verbatim and how to identify the characters speaking. Therefore, there is no restriction in the form AST should adopt. The characteristics of ASTs are decisions that have to be 
made by the describer (Matamala, 2014), concerning features such as the recovering of oral markers, the use of voice, the information provided by the audio describer or the implementation of a dubbing or voice-over effect.

\subsection{Audio Subtitling and its Effects}

Although there is not a lot of research solely concerning the application of AST, two main strategies, techniques or effects, as they are referred to in the literature, are observed when analysing the delivery of ASTs. The distinction between both effects, as they are called in this work, is introduced in Braun \& Orero (2010), in the ISO \& IEC (2016) and in Remael (2014). Such effects take their name from the two main transfer modes in audiovisual translation due to the resemblance of some of their characteristics: dubbing and voice-over effect.

- Voice-over effect: is that in which the original dialogue is heard and the AST is superimposed (Braun \& Orero, 2010, p. 181; ISO/IEC, 2016, p. 12). This effect also presents differences in the synchrony between the original line and the AST. The AST starts "seconds after the original", allowing it to be heard "in the background", which allows the audience to better identify the character speaking (Remael, 2014).

- Dubbing effect: presents synchrony between the AST and the original dialogue. In this case, the original voices are not heard (Braun \& Orero, 2010, p. 181; ISO/IEC, 2016, p.12). The AST, then, replaces the original completely and “often involves more 'acting' on the part of the voice talent" (Remael, 2014).

\section{Multilingualism and Audio Subtitles}

The previous works presented here on audio subtitling show the many possibilities that 
AST can offer. In fact, and as is the case in other transfer modes within audiovisual translation, multilingualism can be revealed in different ways by providing less or more information to the audience. Inspired by Szarkowska et al.'s (2013) application of Sternberg's representation (1981), on the treatment of multilingualism, to subtitles for the deaf and hard of hearing (SDH), the article describes different combinations of sound inputs and information provided by the AD to reveal different degrees of the presence of multilingualism.

\subsection{Sternberg's Representation of Polylingualism}

Sternberg creates a six-level scale for the representation of multilingualism in a text. His representation (1981) was issued primarily for its application to literature. It was later applied to the representation of multilingualism in audiovisual content by O'Sullivan (2011). In short, Sternberg's representation describes the treatment of polylingualism according to the following levels:

(1) Vehicular matching, which implies the presence of the contents in the original foreign language without further information, requiring particular knowledge from both the producer and the receiver of the text. (e.g. She said: “¿Dónde estás?”)

(2) Selective reproduction, which is based on the "intermittent quotation" (p. 225) of the original foreign language; that is, providing the receiver with hints that the text is originally delivered in a foreign language, thus showing the multilingual discourse. (e.g. They commented in a well refined French).

(3) Verbal transposition, which is a form of imitation of some of the features of the foreign language in the language understood by the receiver, such as 
phonetic characteristics or syntactic structures. (e.g. He pronounced every sentence with that strong Italian musicality.)

(4) Conceptual reflection, which has more to do with the socio-cultural than the linguistic; as an example, he mentions the description of a pocket watch by the Lilliputians in Gulliver's Travels when they happen to not know what the object is or the name of it (watch) in their vocabulary, bringing the scale to a higher level of homogenisation of the presence of foreign languages in a text.

(5) Explicit attribution, appears as a "direct statement of the reporter's [...] part concerning the language $[\ldots]$ in which the reported speech was originally made", as Sternberg puts it (231). (e.g. He says in Polish).

(6) Finally, homogenising convention, dismisses all variations in languages that may appear in the text by producing a monolingual discourse.

\subsection{Sternberg's Representation of Polylingualism and SDH}

The scale, embracing the levels of the presence of multilingualism in a text is then applied to the portrayal of multilingualism by using subtitles for the deaf and the hard of hearing. In their article, Szarkowska et al. (2013) differentiate five different levels when dealing with multilingualism. They combine Sternberg's categorisation with other strategies intrinsically belonging to the subtitles for the deaf and the hard of hearing, such as colour coding. Therefore, they present:

(1) Vehicular matching, which is the transcription of the foreign language spoken.

(2) Translation and explicit attribution, that is, translating foreign utterances and indicating the language spoken.

(3) Translation and colour-coding, which includes a translation and colour-coding of the subtitle without specifying the language spoken. 
(4) Explicit attribution, simply telling the receiver that a foreign language is being used.

(5) Linguistic homogenisation, which implies the translation of the utterance without indicating that it is a translation.

They exclude what Stenberg describes as conceptual reflection since it is related to the characteristics of the text translation (semantics) and socio-cultural factors. It is not related to an adaptation of the message to a different code, in this case visual. The strategies they proposed are tested with final users and, as a general outcome, they conclude that deaf and hard of hearing users would prefer more rather than less information about the language spoken in the dialogue.

\section{The Application of Sternberg's Representation on Polylingualism to AST}

Even if the formats of AST and SDH vary enormously, they both make use of different codes that can be combined to achieve different results. Varying amounts of information about multilingualism can be provided. Such information can appear, for instance, in written form in brackets for the SDH or, in its aural counterpart, verbally informed by both the ASTs or AD; or by means of different strategies such as colour-coding for SDH or the audible presence of the original dialogues in AST.

Differences in the characteristics of the texts (written and aural) and the genre (literature and film) imply a reshaping of the notions initially described in Sternberg, as is the case of colour-coding. The variable features in both formats (SDH and AST) allow a parallel scale to be drawn up from the more multilingualism-revealing strategy to the more homogenising strategy as shown in the six-point scale below. The scale is illustrated with the examples in Table 1 . The examples are of a theoretical ilk only. They have been artificially created in order to portray as briefly and clearly as possible 
the explanation of the different categories found in the scale. These are the 6 different levels of the scale proposed:

(1) Vehicular matching, which involves leaving the original soundtrack without any other information, that is, without AST or any information about the original utterance provided in the AD track. The comprehension of the content and the language spoken depends only on the audience's linguistic knowledge. The original content the utterances in a foreign sentence may or may not be subtitled, implying that the comprehension depends solely on the knowledge of the viewer. Such a strategy can be used depending on whether in the non-audio described version such utterance has been translated or not, or it can be conditioned by constraints such as time. In Table 1 below, this is exemplified with the sentence in original English, in the case that the content was to be broadcast in Spain.

(2) Selective reproduction, the implementation of AST with a voice-over effect in the target language. This allows the user to understand that it is a translation. The foreign language is heard in the background without providing further information on the language spoken. The translation into Spanish would be provided in an AST voice-over upon the original English.

(3) Selective reproduction + language information, the AST is provided with a voice-over effect, similar to selective reproduction, and the audio describer provides information on the language spoken. In the example in Table 1, the AST would have the same form as in the selective reproduction but the audio describer would point out that the language spoken is English.

(4) Verbal transposition, in which AST goes beyond the translation by imitating and reproducing some of the patterns of the original foreign language spoken. It 
could be used with both a dubbing or a voice-over effect, since the reproduction of the features concern phonetic, semantic and syntactic structures found in the foreign language that is being portrayed. The example shows the Russian "Spasibo" that is rendered in the audio subtitle into Spanish "Gracias" which imitates the cliché pronunciation of the hard /r/ which the Spanish population relate to Russians speaking foreign languages.

(5) Explicit attribution, which is obtained by providing an AST with a dubbing effect after the language to be spoken is announced. By providing an AST with a dubbing effect, the result is closer to the complete homogenisation of the contents. The example is similar to level 3 in this categorisation but the AST is provided in a dubbing effect. The information provided by the AD is the same as it points out that the original is in English.

(6) Homogenising convention, which is simply based on the complete translation of the original line by means of full dubbing, erasing any traces of the foreign language and creating a monolingual discourse. The example found in the table is a Spanish translation of the original language, no further information is provided, so the audience will not know the original language of the content.

Table 1. Multilingualism-revealing scale for AST based on Sternberg's representation of polylingualism.

As seen in the categorisation of the different levels when revealing multilingualism, the two effects that appear in the literature, dubbing and voice-over, are in themselves strategies to provide audiences with more or less information about the multilingualism found in the content translated. In this proposal, the two effects are complemented by the information provided for the $\mathrm{AD}$, presenting the ASTs to the 
audience in different ways depending on the degree of multilingualism that it is desired the viewer should be shown. Just as in the categorisation of SDH, Sternberg's category "conceptual reflection" has not been used. It has been mentioned above that this level of multilingualism-revealing has to do with sociocultural factors and is not related to the adaptation of the message in a different code.

The categories described here may treat the multilingual audiovisual content by means of different approaches, thus modelling the audiences' reception. It is true, though, that the final strategy proposed will depend on the availability of resources (voice talents, times, professionals, etc.) and the decisions taken by broadcasters and producers. Nevertheless, some observations can be made, from a theoretical point of view.

Strategies such as "vehicular matching", which allow for original languages to be heard without a translation, may be appropriate for audiences who are multilingual or who rely on a linguistic background, in terms of audience characteristics, or in content for which the creator's intention was to leave the audience without the information provided in the dialogues, in terms of product characteristics. It may be better suited to specialised contexts in which the linguistic factor plays an important role.

Other categories, such as "verbal transposition", may result in ASTs exaggerating some of the prototypical features of some language or culture, which may be better suited and appreciated more in humorous genres or for content targeted at a young audience. By portraying "verbal transposition", the way the character sounds is emphasised and this can also be very useful when recognising characters for blind and partially sighted audiences.

The rest of categories could be considered more common, in the sense that they can suit different genres and audiences. Providing information about the language 
spoken in "selective reproduction" may depend on the combination of languages spoken. For instance, it is certainly not the same for a Spanish audience to identify French than it is Korean. For the latter, stating the name of the original language spoken could be very useful. For "explicit attribution", which would sound almost like dubbing, stating the language spoken would be useful when the action revolves around the languages displayed in the action.

In general, it could be argued that the categorisation proposed here follows a continuum that can be matched with the linguistic interest of the audience (or the creators/distributors of the audiovisual content). Multilingualism will be then made more relevant when the audience has greater knowledge of the languages spoken ("vehicular matching") but it will be hidden or masked in categories belonging to the bottom of the categorisation, fully removing its traces ("homogenising convention").

\section{Conclusion and Further Research}

Accessibility services are implemented to ensure access to the media for people with specific needs. In fact, a great amount of research production has centred on techniques, services and strategies that work to enhance access and improve its characteristics. Although it is true that the main use of access services such as AD or AST could be deemed to be the transfer of the information from one code (visual) to another (aural) that would otherwise be lost by the audience, this article has aimed to show the multiplicity of options that this service may offer, thus improving the experience of the audiences and providing more resources to the professionals behind.

Multilingual content presents specific challenges when adapting it to people with sensory disabilities. As suggested by Heiss (2004), the translation of multilingualism may find its way by using different audiovisual transfer modes in the same content. However, such modes combine both the visual and the aural channels and 
are not suitable for use with people with different specificities. Therefore, multilingualism has to be conveyed in different manners that only rely on one channel or the other. For the blind and partially sighted, visual cues and information should be transferred to the audio channel only, resulting in multilingualism being conveyed in AST.

In this regard, ASTs are seen as a hand-crafted creation which adapt an oral dialogue in an original language into a translation using the aural channel only. The portrayal of the multilingual reality of the text is therefore made available in different ways that can enhance or smooth out some of its features across the many levels of representation shown in the scale exposed. The content may be presented in different forms by combining the audio volumes of the original and the translation, or providing different information on behalf of the AD track.

The proposal of different strategies to portray multilingualism in the text being adapted provides a tool for professionals and theorists when facing audiovisual content of various types. The decision to use one strategy or another may be dictated by different factors such as the intention of the creators of the content, their artistic characteristics, the number or type of languages present, or constraints such as time or scene structure.

However, which of the forms proposed here is more effective in terms of translation and experience, and whether these forms can work better depending on the genre of the audiovisual contents or products being translated and adapted is still being investigated. It has been shown that the presence of AST in research is quite recent in relation to other access services for those people with specific visual or reading needs. This opens up a broad field for more research about the treatment and development of audio subtitling as well as its possibilities in terms of applications. 


\section{References}

Almodóvar, P. (2002). Hable con ella. Spain: Warner Sogefilms A.I.E.

Almodóvar, P. (2006). Volver. Spain: Warner Bros. Entertainment.

Benecke, B. (2012). Audio description and audio subtitling in a dubbing country: Case studies. In E. Perego (Ed.), Emerging topics in translation: Audio description (pp. 99-104). Trieste: EUT Edizioni Università di Trieste.

Braun, S., \& Orero, P. (2010). Audio description with audio subtitling - an emergent modality of audiovisual localisation. Perspectives: Studies in Translatology, 18(3), 173-188. https://doi.org/10.1080/0907676X.2010.485687

Campion, J. (1993). The piano. New Zealand: Everard Films.

Corrius Gimbert, M., \& Zabalbeascoa, P. (2011). Language variation in source texts and their translations: The case of L3 in film translation. Target, 23(1), 113-130. https://doi.org/10.1075/target.23.1.07zab

Corrius, M. (2008). Translating multilingual audiovisual texts: Priorities, restrictions, theoretical implications. Autonomous University of Barcelona.

De Higes-Andino, I. (2014). The translation of multilingual films: Modes, strategies, constraints and manipulation in the Spanish translations of It's a Free World .... Linguistica Antverpiensia, 13, 211-231.

Dunquart, P. (2007). Am Limit. Germany: Kinowelt Filmverleih.

Finnish Government. Act on Television and Radio Operations (129/2013) (2010).

Fryer, L. (2013). Putting It Into Words: The Impact of Visual Impairment on Perception, Experience and Presence. University of London.

González Iñárritu, A. (2006). Babel. France, United States and Mexico: Paramount Vantage.

Gottlieb, H. (2004). Subtitles and International Anglification. Nordic Journal of English Studies, 3(1), 219-230.

Greco, G. M. (2016). On Accessibility as a Human Right, with an Application to Media Accessibility. In A. Matamala \& P. Orero (Eds.), Researching Audio Description: New Approaches (pp. 11-34). London: Pelgrave Macmillan.

https://mc.manuscriptcentral.com/mm-ijm Email: RMJM-peerreview@journals.tandf.co.uk 20 
Harrouet, C. (2016). Multilingualism in Audio-Description: Audio-Subtitling. MA

Thesis. Roehampton University. https://doi.org/10.1002/ejoc.201200111

Heiss, C. (2004). Dubbing Multilingual Films: A New Challenge? Meta, 49(1), 208220. https://doi.org/10.7202/009035ar

International Organization for Standardization, \& International Electrotechnical Commission. (2015). Information technology - User interface component accessibility - Part 21: Guidance on audio descriptions (ISO/IEC TS 20071-21). Retrieved from https://www.iso.org/obp/ui/fr/\#iso:std:iso-iec:ts:20071:-21:ed1:v1:en

International Telecommunication Union (Focus Group on Audiovisual Media Accessibility). (2013). Part 5: Final report of activities: Working Group B “Audio/Video description and spoken captions." Geneva.

ISO, \& IEC. (2016). ISO/IEC 20071-25. Information Technology — User interface component accessibility - Part 25: Guidance on the audio presentation of text in videos (including captions, subtitles, and other on screen text).

Jakobson, R. (2000). On linguistic aspects of translation. In L. Venuti (Ed.), The Translation Studies Reader (pp. 232-239). London and New York: Routledge. Retrieved from http://www.stanford.edu/ eckert/PDF/jakobson.pdf

Koolhoven, M. (2008). Oorlogswinter. Netherlands: Benelux Film Distributors. Ljunglöf, P., Derbring, S., \& Olsson, M. (2012). A Free and Open-Source Tool That Reads Movie Subtitles Aloud. In Workshop on Speech and Language Processing for Assistive Technologies (pp. 1-4).

Maszerowska, A., Matamala, A., \& Orero, P. (2014). Audio Description: New perspectives illustrated. Amsterdam: John Benjamins Publishing Company. Matamala, A. (2014). Audio Describing Text on Screen. In A. Maszerowska, A. Matamala, \& P. Orero (Eds.), Audio Description: New Perspectives Illustrated (pp. 103-120). Amsterdam/Philadelphia: John Benjamins Publishing Company.

Matamala, A., \& Orero, P. (2016). Researching Audio Description. London: Palgrave Macmillan.

Matamala, A., Perego, E., \& Bottiroli, S. (2017). Dubbing versus subtitling yet again? 
An empirical study on user comprehension. Babel, 63(3).

Meylaerts, R. (2006). Heterolingualism in/and Translation. Special Issue of Target, 18(1). https://doi.org/10.1075/target.18.1

Meylaerts, R., \& Serban, A. (2014). Multilingualism at the Cinema and on Stage: A Translation Perspective. Linguistica Antverpiensia, New Series - Themes in Translation Studies, 13, 1-13. Retrieved from https://lanstts.uantwerpen.be/index.php/LANS-TTS/issue/current

Miesenberger, K., Klaus, J., \& Zagler, W. (2002). Computers helping people with special needs. In 8th International Conference, ICCHP 2002. Linz, Austria: Springer.

Mihkla, M., Hein, I., Kiissel, I., Räpp, A., Sirts, R., \& Valdna, T. (2014). A System of Spoken Subtitles for Estonian Television. Human Language Technologies - the Baltic Perspective, 268, 19-26. https://doi.org/10.3233/978-1-61499-442-8-19

Nielsen, S., \& Bothe, H. H. (2008). Subpal: A device for reading aloud subtitles from television and cinema. In CEUR Workshop Proceedings (Vol. 415). Retrieved from http://www.scopus.com/inward/record.url?eid=2-s2.084876263872\&partnerID=tZOtx3y1

O’Sullivan, C. (2011). Translating Popular Film. London: Palgrave Macmillan UK. https://doi.org/10.1057/9780230317543

Orero, P. (2011). The audiodescription of spoken, tactile and written language in $\mathrm{Be}$ with me. In A. Matamala, J.-M. Lavaur, \& A. Serban (Eds.), Audiovisual Translation in Close-up (pp. 239-255). Bern: Peter Lang.

Remael, A. (2012). Audio Description with Audio Subtitling for Dutch Multilingual Films: Manipulating Textual Cohesion on Different Levels. Meta: Journal Des Traducteurs, 57(2), 385-407. https://doi.org/10.7202/1013952ar

Remael, A. (2014). Combining audio description with audio subtitling. In A. Remael, N. Reviers, \& G. Vercauteren (Eds.), ADLAB Audio Description Guidelines. Retrieved from http://www.adlabproject.eu/Docs/adlab book/index.html\#combining-ad

Reviers, N., \& Remael, A. (2015). Recreating multimodal cohesion in audio description: A case study of audio subtitling in Dutch multilingual films. New 
Voices in Translation Studies, 13(1), 50-78.

Sepielak, K. (2016). Synchronization Techniques in Multilingual Fiction: Voiced-Over Films in Poland. International Journal of Communication, 10, 1054-1073.

Sternberg, M. (1981). Polylingualism as reality and translation as mimesis. Poetics Today, 2(4), 221-239.

Swedish Government. Culture and Accessibility - Public Radio and Television 20142019 (2014).

Szarkowska, A., \& Mączyńska, M. (2011). Text-to-speech audio description with audio subtitling to a non-fiction film. A case study based on La Soufriere by Werner Herzog. University of Warsaw.

Szarkowska, A., Zbikowska, J., \& Krejtz, I. (2013). Subtitling for the deaf and hard of hearing in multilingual films. International Journal of Multilingualism, 10(3), 292-312. Retrieved from https://xpv.uab.cat/doi/full/10.1080/,DanaInfo=.awxyCxftknxxwu0sOs54+147907 18.2013.766195?scroll=top\&needAccess=true

Tarantino, Q. (2009). Inglorious Basterds. United States: Weinstein Company, The.

Thrane, L. K. (2013). Text-to-Speech on Digital TV: An Explanatory Study of Spoken Subtitles on DRISyn. IT University of Copenhagen.

van den Berg, R. (2010). Tirza. Netherlands: Independent Films. van den Berg, R. (2012). Süskind.

Verboom, M., Crombie, D., Dijk, E., \& Theunisz, M. (2002). Spoken Subtitles: Making Subtitled TV Programmes Accessible. In K. Miesenberger, J. Klaus, \& W. Zagler (Eds.), Computers Helping People with Special Needs. 8th International Conference, ICCHP 2002 (pp. 295-302). Berlin, Heidelberg: Springer-Verlang. Voellmer, E., \& Zabalbeascoa, P. (2014). How multilingual can a dubbed film be? Language combinations and national traditions as determining factors. Linguistica Antverpiensia, New Series, 13, 232-250. 
Table 1. Multilingualism-revealing scale for AST based on Sternberg's representation of polylingualism.

\begin{tabular}{|c|c|}
\hline $\begin{array}{l}\text { Vehicular matching: } \\
\text { original soundtrack }\end{array}$ & [Original audio] Hello, how are you? \\
\hline \multirow{2}{*}{$\begin{array}{l}\text { Selective reproduction: } \\
\text { AST in voice-over effect }\end{array}$} & [Original audio] Hello, how are you? \\
\hline & [AST] Hola, ¿cómo estás? \\
\hline \multirow{2}{*}{$\begin{array}{l}\text { Selective reproduction + language info: } \\
\text { AST in voice-over effect + language } \\
\text { info }\end{array}$} & [Original audio] Hello, how are you? \\
\hline & $\begin{array}{l}\text { [AST] Hola, ¿cómo estás? } \\
\text { [Audiodescriber] En inglés }\end{array}$ \\
\hline \multirow{2}{*}{$\begin{array}{l}\text { Verbal transposition: } \\
\text { reproduction of original patterns }\end{array}$} & [Original audio] Spasibo \\
\hline & [AST] G[r]acias \\
\hline \multirow{2}{*}{$\begin{array}{l}\text { Explicit attribution: } \\
\text { AST in dubbing effect + language info }\end{array}$} & $\begin{array}{l}\text { [Original audio removed] Hello, how } \\
\text { are you? }\end{array}$ \\
\hline & $\begin{array}{l}\text { [AST] Hola, ¿cómo estás? } \\
\text { [Audiodescriber] En inglés }\end{array}$ \\
\hline $\begin{array}{l}\text { Homogenising convention: } \\
\text { AST in dubbing effect }\end{array}$ & [AST] Hola, ¿cómo estás? \\
\hline
\end{tabular}

